\title{
Educação em saúde no controle do Aedes aegypti - da teoria à prática
}

\author{
Health education in the control of Aedes aegypti - from theory to practice \\ Educación sanitaria en el control del Aedes aegypti - de la teoría a la práctica
}

Recebido: 05/07/2021 | Revisado: 09/07/2021 | Aceito: 10/07/2021 | Publicado: 22/07/2021

\author{
Taiana Gabriela Barbosa de Souza \\ ORCID: https://orcid.org/0000-0002-1913-7694 \\ Universidade Federal de Mato Grosso do Sul, Brasil \\ E-mail: taiana.souza@ufms br \\ Eduardo José de Arruda \\ ORCID: https://orcid.org/0000-0002-9835-467X \\ Universidade Federal da Grande Dourado, Brasil \\ E-mail: ejarruda@gmail.com \\ Alex Martins Machado \\ ORCID: https://orcid.org/0000-0002-6118-2042 \\ Universidade Federal de Mato Grosso do Sul, Brasil \\ E-mail: alex.machado@ufms.br \\ Antônio Pancrácio de Souza \\ ORCID: https://orcid.org/0000-0003-2544-1120 \\ Universidade Federal de Mato Grosso do Sul, Brasil \\ E-mail: alex.machado@ufms.br
}

\begin{abstract}
Resumo
Os surtos epidêmicos de dengue no Brasil têm sido cada vez mais frequentes. No ano de 2020 a pandemia de COVID19 associada aos casos de dengue, zika e chikungunya expuseram a capacidade finita do sistema de saúde, o que torna o tema dengue ainda mais urgente. Todos os anos somos alertados sobre a importância de se eliminar criadouros do mosquito Aedes aegypti (Linnaeus, 1762), por meio de campanhas educativas nas mídias locais, nas redes sociais, entre outros. A partir desse cenário, nesse trabalho buscamos elencar os principais motivos apresentados por alguns autores para essa baixa adesão da população, bem como, apresentar as principais soluções apontadas na literatura científica. Foram apontadas diretrizes gerais a fim de que os profissionais de saúde e educação desenvolvam alternativas capazes de integrar a saúde e educação, além de promover um maior engajamento da população às práticas de controle do vetor.
\end{abstract}

Palavras-chave: Educação em saúde; Tríplice epidemia; Antropofilía; Pesquisa-ação; Ensino.

\begin{abstract}
Epidemic outbreaks of dengue in Brazil have been increasingly frequent. In 2020, the COVID19 pandemic associated with dengue, zika and chikungunya cases exposed the finite capacity of the health system, which makes the dengue theme even more urgent. Every year we are warned about the importance of eliminating breeding grounds for the Aedes aegypti mosquito (Linnaeus, 1762), through educational campaigns on local media, on social networks, among others. Even so, the population's low adherence to measures aimed at mosquito control is perceived. From this scenario, in this work we seek to list the main reasons presented by some authors for this low population adherence, as well as to present the main solutions pointed out in the scientific literature. General guidelines were pointed out so that health and education professionals develop alternatives capable of integrating health and education, in addition to promoting greater population engagement with vector control practices.
\end{abstract}

Keywords: Health education; Triple epidemic; Anthropophilia; Action research; Teaching.

\section{Resumen}

Los brotes epidémicos de dengue en Brasil han sido cada vez más frecuentes. En 2020, la pandemia COVID19 asociada a casos de dengue, zika y chikungunya expuso la capacidad finita del sistema de salud, lo que hace que el tema del dengue sea aún más urgente. Cada año se nos alerta sobre la importancia de eliminar los criaderos del mosquito Aedes aegypti (Linnaeus, 1762), a través de campañas educativas en medios locales, redes sociales, entre otros. A partir de este escenario, en este trabajo buscamos enumerar las principales razones presentadas por algunos autores para esta baja adherencia poblacional, así como presentar las principales soluciones señaladas en la literatura científica. Se identificaron pautas generales para que los profesionales de la salud y la educación desarrollen alternativas capaces de integrar la salud y la educación, además de promover una mayor participación de la población en las prácticas de control de vectores.

Palabras clave: Educación para la salud; Triple epidemia; Antropofilia; Investigación para la acción; Enseñando. 


\section{Introdução}

A partir dos anos 70 a falta de infraestrutura urbana de abastecimento de água, esgoto e de limpeza urbana; aumento exponencial de materiais não biodegradáveis descartáveis de plástico e vidro, somado às mudanças climáticas e processo de urbanização acelerado contribuíram para o avanço inicial da epidemia de Dengue, que posteriormente seria somada com as epidemias de Zika e Chikungunya em todo o território nacional (Brasil, 2002).

É importante destacar que essas epidemias também possuem uma forte relação com os fatores intrínsecos do vetor Aedes aegypti, tais como, plasticidade comportamental, rápido desenvolvimento, resistência dos ovos à dessecação, competência vetorial para várias arboviroses e antropofilia (adaptação aos hábitos humanos) sendo necessário que as ações de controle levem em conta cada um destes aspectos (Carvalho \& Moreira 2017; Honório et al., 2020; Aragão et al., 2019; Mukherjee et al., 2019).

Até o final da década de oitenta, o Brasil apresentava uma baixa incidência de casos de dengue ( 3,8 casos por 100.000 habitantes), mudando assustadoramente e de maneira alarmante desde a década de 90, principalmente, nas regiões nordeste e sudeste, com números oscilando entre 65,6 até quase 500 casos por 100.000 habitantes. Estas altas incidências estimularam a implantação e execução do PNCD - Plano Nacional de Controle da Dengue (Ferreira et al., 2009), sendo importante ressaltar que dos dez componentes do PNCD, o sexto diz respeito às ações integradas em saúde, comunicação e mobilização social, onde estão inseridas as ações educativas (Brasil 2002).

É observado que durante as crises epidêmicas de dengue as pessoas buscam por soluções milagrosas, muitas vezes emergenciais e, muitas vezes, comprovadamente ineficazes para o controle do mosquito, como por exemplo, o cultivo da planta crotalária para atrair libélulas por serem predadores do mosquito Aedes aegypti, porém é necessário que esta população procure e tenha acesso à informações confiáveis, explicando de maneira científica a eficiência e/ou ineficiência de certas medidas, reforçando que a eliminação criadouros continua sendo a medida mais eficaz em relação ao controle deste vetor, e que esta ação não deve ser realizada somente nos momentos críticos ou epidêmicos, e sim permanentemente, como forma de evitar estes períodos epidêmicos (Brito et al., 2020).

É sabido que para o controle e a diminuição da ocorrência de arboviroses, o manejo dos mosquitos vetores, bem como ao controle de criadouros são considerados importantes por poderem promover mudanças positivas no que se refere ao controle vetorial, porém para isso, a educação em saúde é uma ferramenta fundamental para inculcar, na população, as medidas e manejos dos vetores, no entanto estas práticas são pouco adotadas pela população, ou não são mantidas a longo prazo (Purnama, et al., 2020; Heydari et al., 2017).

A associação entre controle populacional de formas imaturas como ovos e larvas e até do inseto adulto (alado) devem ser estimuladas a partir de estratégias educacionais, fornecendo a população ferramentas para uma ação participativa no controle populacional dos vetores, e não apenas a observação das atividades por equipes especiais de controle de mosquitos. Assim, a população deve ser estimulada a manter uma forma proativa às questões relacionadas à educação em saúde por programas contínuos de informação e formação para o enfrentamento, sendo estes fornecidos pelas autoridades competentes, com auxílio de instituições de ensino (Chaves et al., 2020)

Apesar dessa necessidade de implantação de mecanismos de educação e conscientização da população sobre as doenças transmitidas por vetores ainda é escasso no ensino (fundamental, médio e superior) a abordagem dessa temática. Neste cenário, faz-se necessário o estímulo a campanhas educacionais, a todo tempo, nas escolas, promovendo mobilização social e voluntária para aumento do controle, bem como o conhecimento e dos riscos à saúde propiciados por estas doenças (Macedo et a., 2021; Parker et al., 2019, Sulistyanwati et al., 2019). Assim, os trabalhos de educação para conscientização da sociedade sobre o controle do vetor A. aegypti pode corroborar para o aumento no conhecimento sobre o tema, e a tomada de protagonismo por parte da população no efetivo controle dos vetores. 
Entretanto, como visto em alguns municípios, a educação em saúde não tem sido traduzida na eliminação dos criadouros do mosquito, independente do estrato social ser mais ou menos favorecido, sendo isto possivelmente atribuído à falta de comprometimento da população com as ações de combate, preocupação da população somente nos momentos de epidemia ou até mesmo por falta de diálogo entre o poder público e a população (Lutinski 2013, Santos et al. 2012, Rangel 2008, Sales 2008, Donalisio et al. 2001).

Neste contexto, diante da dificuldade constatada da população em adotar permanentemente as práticas de controle deste vetor, mesmo após receber a devida orientação por meio de campanhas educativas, nos objetivamos fazer uma revisão com produções científicas das duas últimas décadas no Brasil, mostrando e priorizando os trabalhos em que os autores discutiram as razões para a falta de comprometimento, adesão e efetividade das ações, bem como de soluções para esse grave problema de saúde pública no Brasil.

\section{Metodologia}

O presente trabalho trata-se de uma pesquisa documental qualitativa realizada em base de literatura disponíveis em artigos científicos e/ou livros, seguindo metodologia de pesquisa previamente instaurada e validada por pesquisadores como Pereira et al. (2018) e Ludke e Andre (2013). Vale destacar que a pesquisa qualitativa possibilita uma visão holística e flexível do objeto de estudo, possibilitando compreender todos os diferentes pontos de vista bem como avaliar cada aspecto do estudo, como descrito por Mazzoti e Gewandsznnajder (2002).

A pesquisa documental foi realizada em bases de dados de artigos científicos: Scielo, Bireme e Pubmed, selecionando artigos em qualquer idioma, que abordasse a temática proposta, sendo usados como palavras chave: Controle Dengue; educação para controle de arboviroses e campanhas de prevenção (nos diferentes idiomas), tendo como período de busca artigos publicados nos últimos 20 anos $(2001$ - 2021). Após a obtenção dos artigos, os mesmos foram analisados e selecionados todos os artigos que colaborassem com a temática proposta.

Também foram pesquisados e analisados documentos do Ministério da Saúde (Brasil) referentes a campanhas e medidas de controle à Dengue, estabelecidas pelo governo federal, no mesmo período de seleção de artigos.

\section{Resultados e Discussão}

\subsection{Motivos para a baixa adesão da população.}

Em 2001, Donalisio e colaboradores (2001) já apontavam fragilidades no controle do A. aegypti relacionados a pouca adesão da população às orientações do poder público, destacando a importância como subsídio de (re)orientar ações educativas das equipes de controle de vetores, bem como avaliar um instrumento simplificado para acompanhamento do impacto do programa local de controle do dengue. Neste estudo, os autores ressaltam a importância de considerar formas de linguagem mais efetivas nas ações educativas, o objetivo de obter um maior engajamento da população na eliminação de criadouros, fazendo a educação em saúde traduzir-se em mudança comportamental para o controle do mosquito, especialmente no ambiente domestico e peridomestico.

Por outro lado, Madeira et al. (2002) argumenta que o conhecimento, fornecido a população é muitas vezes fragmentado e até mesmo relativizado, o que contribui para o distanciamento entre o que a população sabe e o que realmente faz e pratica; como por exemplo, não se deve acumular recipientes considerados como lixo; cada um tem o seu conceito do que é lixo e, a partir disso, poderá deixar disponível um criadouro porque aquele recipiente está tendo alguma utilidade, seja para água aos animais, armazenamento de água, entre outros. Além disso, Brito et al. (2020) alertam para métodos de controle comprovadamente ineficazes como a crotalária que induzem a população a aderir a práticas inócuas de controle do mosquito, 
que ao não surtirem o efeito esperado pela população contribui para o afastamento ou não participação efetiva no controle dos vetores.

Corroborando a isto, Chiaravalloti et al. (2002) pontua alguns outros fatores que interferem na adesão da comunidade às práticas profiláticas orientadas pelo poder público para o combate ao mosquito, sendo elas: a falta de manutenção dos espaços públicos por parte do próprio ente público que deveria ser exemplo; falta de interação entre o serviço público de combate e a população; desconsideração do saber popular nas atividades práticas preventivas de controle do mosquito; e a associação errônea de ambientes sujos com a presença do vetor, bem como a de ambientes limpos a ausência dos mesmo. Os autores salientam que apesar de existir forte associação da falta de higiene com a presença de criadouros, não está correto acreditar que em casa limpa não tem espaço para o mosquito, pois, os criadouros ocorrem em qualquer ambiente, basta que haja recipientes com água disponível (Chiaravalloti et al. 2002, Rangel 2008).

Reis e Cunha (2013) corroboram as observações anteriormente citadas, e listam quatro fatores básicos para ocorrência de dengue e a não participação da população, listados por profissionais da saúde do segundo maior município do estado de Mato Grosso do Sul (Dourados/MS), sendo eles: a falta de cuidado com o ambiente; o descrédito na ocorrência e na gravidade da doença; serviços relacionados ao controle da dengue sendo realizados ou difundidos somente em período epidêmicos; e situação socioeconômica da comunidade atendida (apesar que a doença ocorre em todas as camadas da sociedade). Além disso, apontam que ações que o poder público às vezes falha, por exemplo, lixão a céu aberto, bromélias nos espaços públicos, ou mesmo a incapacidade que esses profissionais têm em comunicar com eficiência metodológica de forma a produzir mudanças comportamentais no público alvo também são importantes entraves na aproximação e participação da população nas medidas de controle, servindo como justificativas da população à não adesão às medidas profiláticas.

Ainda, os autores argumentam que a falta de adesão da comunidade às ações preventivas e o comodismo das pessoas é uma consequência de ações assistencialistas do estado. O hábito da população é visto como imutável pelos profissionais, o que no caso da dengue acrescenta-se ao fato de que não ocorre todos os anos uma epidemia, assim os bons hábitos de cuidado do ambiente não ficam arraigados nas pessoas. Por outro lado, o descrédito com a doença também é um entrave que passa pela educação para cidadania, sendo necessário o desenvolvimento de uma responsabilidade coletiva a qual deve ser estimulada permanentemente.

Oliveira e Lima 2013 e Heymann e Dar 2014, corroboram a estes achados, mostrando que os fatores que estão associados ao descrédito e não participação da população são a infraestrutura urbana precária, em especial a limpeza e manutenção urbana. Diante disso, é importante investir em capacitação contínua e contextualizada, bem como metodologias que tenham maior impacto na mudança de hábitos das pessoas, tornando o controle de vetores no domicílio e no peridomicílio uma atividade diária (Santos et al., 2012).

Neste contexto, Rangel (2008) debate amplamente a diferença entre discurso e prática no controle do vetor da dengue, criticando as atuais medidas como uma modelagem centralizada, vertical e unidirecional, orientadas pela visão de que informações e conhecimentos estão concentrados e devem ser difundidos, e de que a comunicação é uma questão de aperfeiçoamento de técnica de transmissão de mensagens e de adequação de linguagem para que o receptor apresente mudanças de hábitos e comportamentos. Os autores exemplificam que em suas pesquisas sobre campanhas educativas, percebeu-se que as informações não eram fornecidas por completo a população, e que essa fragmentação do conhecimento, podia induzir o cidadão a erros, sendo um claro exemplos a banalização do uso do paracetamol no tratamento dos sintomas da Dengue.

Em seus estudos, o autor observou alguns problemas relativos às práticas de educação, comunicação e mobilização comunitárias no controle da dengue, destacando-se entre elas, o uso da palavra guerra (Guerra ao mosquito) remetendo à história da saúde pública no Brasil na luta contra inimigos biológicos, o que não cabe hoje. Além disso, percebeu-se a visão 
dos agentes como incapacitados para encaminhar demandas populares com respeito a outros condicionantes, como a coleta de lixo, o abastecimento de água e a preservação do espaço público. Por outro lado, a constante explicação de que a população é resistente, ignorante e pouco ativa não leva em conta os determinantes sociais e culturais, assim, as ações apenas estigmatizam locais e pessoas, comprometendo, inclusive, a construção de laços de solidariedade entre os moradores de periferias da cidade. É importante considerar, entretanto, que nessa interação a confiança e credibilidade são essenciais em ações de educação em saúde na comunidade.

Sales (2008) desta que as práticas educativas em saúde são divergentes, a ação transformadora é ineficaz para impactar a doença e ainda acrescenta como dificuldades as fragilidade e ações pontuais; conteúdo das mensagens educativas descontextualizadas; estratégias autoritárias e coercitivas, ausência de políticas públicas, limites entre a UBS e a população; ênfase às campanhas sanitárias; bem como a falta de diálogo entre os profissionais e a população e vice-versa, predominando o saber técnico sobre o usuário.

As deficiências nas ações do Estado e a imagem dos serviços públicos de saúde veiculada pela mídia também afetam a credibilidade do poder público, segundo Ferreira et al. (2009). Em seus estudos observa-se que em municípios com baixo analfabetismo, alta coleta de lixo, alta proporção de instalações sanitárias há correlação com uma boa classificação do município em relação ao controle da dengue. Corroborando a isto, Gonçalves et al. (2015) evidenciam que às condições socioeconômicas desfavoráveis, no geral, favorecem a incidência de comportamentos propícios à proliferação do mosquito $A$. aegypti no ambiente intra e peridomiciliar, principalmente em áreas com baixa ou nenhuma infraestrutura de abastecimento de água, coleta de resíduos sólidos e saneamento geral, e que quando questionada a população quanto a sua participação, colocam a falta destes serviços oferecidos pelo poder público como justificativa para a não participação nas medidas profiláticas.

Com o intuito de resumir e agrupar os principais motivos da falta de participação e envolvimento da população nas medidas de controle, apresentada pelos diferentes autores, foi criada uma tabela que evidência estes dados (Tabela 1). 
Tabela 1. Principais motivos para baixa adesão da população às campanhas educativas em ações de controle do vetor Aedes aegypti.

\begin{tabular}{|c|c|c|c|}
\hline Título do Artigo & Autores & $\begin{array}{l}\text { Periódico (v. n. pp. e } \\
\text { ano) }\end{array}$ & Motivos e dificuldades na adesão da população. \\
\hline $\begin{array}{l}\text { Education in primary school } \\
\text { as a strategy to control } \\
\text { dengue }\end{array}$ & $\begin{array}{l}\text { Madeira, NG. et } \\
\quad \text { al. }\end{array}$ & $\begin{array}{l}\text { Rev. Soc. Bras. Med. } \\
\text { Trop. 35, 221-226, } \\
\text { 2002. }\end{array}$ & $\begin{array}{l}\text { Relativização do conhecimento. Conhecimento } \\
\text { oferecido a população é fragmentado. }\end{array}$ \\
\hline $\begin{array}{l}\text { Avaliação sobre a adesão às } \\
\text { práticas preventivas do } \\
\text { dengue: o caso de Catanduva, } \\
\text { São Paulo, Brasil. }\end{array}$ & $\begin{array}{l}\text { Chiaravalloti, VB. } \\
\text { Et al. }\end{array}$ & $\begin{array}{l}\text { Cad. Saúde Pública, } \\
18,1321-1329,2002\end{array}$ & $\begin{array}{l}\text { Falta de exemplo de órgãos públicos na limpeza de } \\
\text { espaços públicos. Falta de interação do setor } \\
\text { público e a população. } \\
\text { Desconsideração do saber da população pelo poder } \\
\text { público. Associação errônea pela população entre } \\
\text { ambiente sujo e mosquitos e ambiente limpo e falta } \\
\text { de mosquitos. }\end{array}$ \\
\hline $\begin{array}{l}\text { Dengue: } \\
\text { comunicação e mobilização } \\
\text { na perspectiva do controle - } \\
\text { propostas inovadoras }\end{array}$ & Rangel SML. & $\begin{array}{c}\text { Interface - } \\
\text { Comunicação, Saúde, } \\
\text { Educação, 12, 433- } \\
441,2008 .\end{array}$ & $\begin{array}{l}\text { Crença errônea da relação de ambientes sujos e } \\
\text { mosquitos e ambiente limpo e falta de criadouros. } \\
\text { Falta de autonomia dos agentes para acolhimento } \\
\text { das demandas da população (Coleta de lixo, } \\
\text { limpeza urbana, entre outras). Crenças do poder } \\
\text { público da incapacidade ou ignorância da } \\
\text { população na realização de seu papel no combate } \\
\text { ao mosquito. Falta de consulta a população } \\
\text { (Medidas produzidas pelo sistema público sem } \\
\text { levar em consideração o conhecimento e } \\
\text { participação popular). }\end{array}$ \\
\hline $\begin{array}{l}\text { Ações de educação em saúde } \\
\text { para prevenção e controle da } \\
\text { dengue: um estudo em Icaraí, } \\
\text { Caucaia, Ceará. }\end{array}$ & Sales, FMD & $\begin{array}{c}\text { Ciência \& Saúde } \\
\text { Coletiva, 13, 175-184, } \\
2008 .\end{array}$ & $\begin{array}{l}\text { Práticas educativas divergentes. Fragilidade das } \\
\text { ações pontuais. Mensagens educativas } \\
\text { descontextualizadas. Estratégias autoritárias e } \\
\text { coercitivas com ausência de políticas públicas } \\
\text { eficientes. Ênfase às campanhas sanitárias. Falta de } \\
\text { diálogo entre os profissionais e a população. }\end{array}$ \\
\hline $\begin{array}{l}\text { Evolução histórica dos } \\
\text { programas de prevenção e } \\
\text { controle da dengue no Brasil }\end{array}$ & Ferreira, BJ. et al. & $\begin{array}{c}\text { Ciência \& Saúde } \\
\text { Coletiva, 14, 961-972, } \\
2009 .\end{array}$ & $\begin{array}{l}\text { Ineficiência das ações do estado. Imagem do poder } \\
\text { público pela população afeta a credibilidade e a } \\
\text { adesão pública. Características socioeconômicas da } \\
\text { população afeta diretamente na adesão e no êxito } \\
\text { das medidas de controle. }\end{array}$ \\
\hline $\begin{array}{l}\text { Contribuições recentes sobre } \\
\text { conhecimentos, atitudes e } \\
\text { práticas da população } \\
\text { brasileira acerca da dengue. }\end{array}$ & $\begin{array}{l}\text { Gonçalves, RP. et } \\
\text { al. }\end{array}$ & $\begin{array}{l}\text { Saúde e Sociedade, } \\
24,578-593,2015 .\end{array}$ & $\begin{array}{l}\text { Condições socioeconômicas desfavoráveis } \\
\text { desfavorecem as medidas de controle e o êxito das } \\
\text { mesmas. }\end{array}$ \\
\hline
\end{tabular}

Fonte: Autores.

\subsection{Alternativas para maior adesão da população}

Atualmente, o tema dengue é abordado nas escolas do Brasil devido a que as Diretrizes Nacionais de Prevenção e Controle das Epidemias de Dengue orientam dessa forma, entretanto, Assis et al. (2013a) verificaram erros conceituais, emprego de ilustrações inadequadas e descontextualização sociocultural do conteúdo durante pesquisa em coleções de ciências do PNLD 2008 e 2011 e de biologia do PNLEM 2009 (em um total de 114 exemplares). Essas falhas comprometem a capacidade colaborativa da escola no controle do mosquito A. aegypti. Assis et al. (2003b) argumentaram que a disseminação de conceitos incorretos, por exemplo, pode potencializar comportamentos de risco por parte desses indivíduos e pela população. Assim, estes autores enfatizam a necessidade de cooperação entre cientistas, professores e escola, a fim de criar e 
fornecer as escolas conteúdos corretos sobre a temática, em linguagem adequada e que seja capaz de estimular, nas crianças e adolescentes uma consciência e um protagonismo quanto a medidas de controle e profilaxia contra estes vetores.

Dentro deste contexto, de falhas na educação em saúde, no que se refere a controle de mosquitos vetores e arbovírus por estes transmitidos, procurou-se a seguir, apresentar soluções apontadas por alguns autores para aumentar a adoção de práticas de controle do mosquito no Brasil, bem como de empoderar a população para tornar-se um agente de controle principalmente no ambiente domiciliar e peri-domiciliar.

Entre as ações para maior adesão da população, uma abordagem multissetorial colaborativa é imprescindível para melhorar o controle de infecções emergentes, e, além disso, as medidas de intervenção devem demonstrar claramente que funcionam, ter um bom custo/benefício e sustentabilidade (Heymann \& Dar 2014). Assim, uma proposta inovadora na educação em saúde tem o desafio não só de educar e conscientizar, mas de propor mudanças na cultura, principalmente nos aspectos de construção de ações democráticas, descentralizadas e eficientes (Rangel, 2008).

Um exemplo deste tipo de ação vem ocorrendo nos principais municípios do Mato Grosso do Sul, estando em funcionamento por pelo menos cinco anos. Trata-se de um comitê municipal de controle do mosquito da dengue, composto por representantes de vários segmentos da sociedade, a fim de debater todos os temas relacionados ao objetivo final de combate ao mosquito. Esse comitê possibilita que as práticas de comunicação, educação e mobilização social sejam vinculadas a um conjunto ampliado de ações intersetoriais, por exemplo, de natureza econômica (controle da produção de descartáveis), jurídica (responsabilização das indústrias pelo destino final) e educação (ações educativas à população), conforme recomendado por Rangel (2008).

Fernandes et al. (2017) enfatiza a importância da mobilização social e participação efetiva da sociedade na concepção, implementação, monitoramento e avaliação vigilância em saúde para que possamos obter melhores resultados no controle da dengue no Brasil. A participação social associada ao manejo ambiental no controle do vetor A. aegypti traz resultados comprovadamente superiores ao manejo ambiental promovido pelo poder público sem o devido engajamento da população (Caprara et al., 2015)

Corroborando a isto, Lutinski et al., 2013 recomendam a implantação de políticas públicas de educação ambiental em saúde para a separação e destinação adequada dos resíduos sólidos e melhorias no sistema de abastecimento público de água. É uma recomendação importante porque, como foi mencionado por Gonçalves et al. (2015), a infraestrutura insuficiente também afeta a adesão das pessoas às práticas de controle de A. aegypti.

Por outro lado, Chiaravalloti et al., (2002) e Sales (2008) defendem a valorização do conhecimento popular, adaptação de uma linguagem técnica ao cotidiano das pessoas, de modo a aproximar o discurso da prática, contribuindo para a cidadania do indivíduo, e assim, aumentar a adesão dos moradores às práticas profiláticas de controle dos mosquitos vetores. É importante que as ações educativas sejam contínuas utilizando diferentes tipos de mídia, ao contrário do observado em ações campanhistas, pontuais e descontínuas (Rangel, 2008, Santos et al., 2012), caso contrário, mesmo casos bem sucedidos como relatado por Carneiro et al. (2016) e Souza (2017) no município de Pedra Branca, no sertão do Ceará por meio de ações coordenadas por 15 anos podem ser perdidos pela descontinuidade.

Ainda, Rangel (2008) destaca alguns princípios e diretrizes para ações de comunicação, educação e participação para o debate: participação democrática; sensibilidade cultural; multimidiatização: meios e recursos disponíveis e preferenciais; dialogicidade/criação de espaços de conversação; mobilização e educação por pares; capacitação profissional e comunitária; antecedência de pesquisas culturais (crenças, valores, saberes, percepções); pesquisas avaliativas das práticas de educação, comunicação e participação para o controle da dengue.

Salienta-se ainda, que as escolas exercem um papel fundamental na busca por solução a esse problema, entretanto, é necessário um trabalho mais amplo e outras práticas contínuas por parte das escolas associado à comunidade, com potencial de 
ser mais eficiente do que ações pontuais devido a escola e professores terem instrumentos institucionais para a realização de um trabalho integrado entre escola e a comunidade, formando o discente como agente promotor de saúde (Santos et al., 2012, Lutinski et al., 2013). Um exemplo disso, foi relatado por Brassolatti e Andrade (2002) que registraram aumento do conhecimento, e uma sensível diminuição de criadouros do mosquito nos ambientes escolares e nos lares dos alunos envolvidos em uma ação educativa articulada entre profissionais de saúde e educação, na cidade de Campinas -SP.

Oliveira e Lima (2013), também corroboram a importância da educação no controle de vetores, afirmando que a educação não pode ser somente informativa, devendo ser formativa, construtiva e ressignificativa, o tempo todo e em todos os lugares; nas ações preventivas, os princípios da Promoção da Saúde devem ser levados ao exercício na comunidade, valorizando as identidades individuais, com dignidade, ética e responsabilidade, além da solidariedade e sentimento de pertencimento a uma coletividade. Os autores ainda ponderam que deve se considerar as particularidades da área alvo, a vida cotidiana, as relações interculturais, uma vez que o processo saúde-doença está fortemente determinado pelas condições de vida e trabalho dos indivíduos e coletividades, e que as intervenções do poder público devem ser estabelecidas com políticas públicas intersetoriais, mobilização social e empoderamento das comunidades em articulação com lideranças locais para atuar sobre os determinantes sociais da saúde, evitando assim, medidas imediatistas, fragmentadas, tomadas nos períodos epidêmicos.

Frente a isto, Lenzi e Coura (2004) discute muito bem sobre os componentes de informação, comunicação e educação sobre a dengue, evidenciando pontos chave para a melhora da ação, sendo estas: e fizeram as seguintes colocações: Mudar o caráter campanhista, sendo mais horizontalizado, incluindo por exemplo, grupos sociais organizados na discussão de $o$ quê e como informar; divulgação permanente, inclusive na mídia, evitando um período de silêncio em que a população relaxa no controle dos focos do mosquito; maior abrangência quanto aos tópicos abordados; esclarecimento em linguagem simples sobre os sintomas de dengue clássica e severa para evitar agravamento dos quadros, ou óbitos; alertar sobre os riscos da automedicação; e respostas às dúvidas mais frequentes de forma clara e com linguagem acessível.

Com o intuito de criar medidas para implantação de políticas de prevenção menos verticalizadas, considerando os interesses, necessidades, desejos e visões de mundo da comunidade, Gonçalves et al. (2015) sugeriram algumas, ações que podem melhorar o engajamento da população, sendo estas: incentivar a lógica de integração do Programa de Saúde ao nível comunitário para a não superposição de atividades e ganho de escala na consecução das atividades, além de uma boa receptividade da população; informar, educar e comunicar a comunidade de maneira simples, objetiva e efusiva de acordo com as particularidades de cada contexto específico; desverticalizar o modelo nacional de controle, incentivando alternativas para o controle vetorial doméstico ou de microrregiões e entornos com abordagem multissetorial por meio de práticas de ações e práticas educativas continuada; empoderar a população com informações e ações educativas em saúde pública para enfrentamentos e que ocupe posição privilegiada na formulação das políticas de saúde referentes à dengue e outras doenças vetoriais; desenvolver o sentimento de pertença e responsabilidade individual de todos em detrimento da culpabilização dos vizinhos, principalmente entre as mulheres; suplantar equívocos ainda arraigados, como a associação do problema da dengue à falta de higiene, a relação entre casa limpa e ausência de criadouros e, especialmente, superar a crença de que, nos períodos interepidêmicos, a queda dos casos da doença é resultado do seu controle de forma contínua e não esporádica; incentivar a promoção e a educação em saúde no combate à doença durante o ano inteiro, a despeito das atividades sazonais, tais como cobertura jornalística e campanhas majoradas apenas durante a iminência de epidemias; e promover o diálogo entre ciência e senso comum a fim de que diversos conhecimentos sociais possam servir de suporte para a implementação de estratégias que sejam adequadas, sendo este um diálogo aberto para o ensinar e o aprender, mas, sobretudo, para construir juntos ações de benefícios coletivos. 
Corroborando a estas estratégias, Mafra e Antunes (2015) propuseram cinco pressupostos relacionais para estratégias de comunicação em cenários públicos de experienciação em dengue e doenças relacionadas: 1. Não existem estratégias mágicas, isto é, as instituições públicas não estão desconectadas das experiências da comunidade, os processos estratégicos de comunicação devem ser conduzidos como forma de interpretar a doença, não como soluções únicas na forma como os sujeitos experimentam essa questão; 2. As estratégias de comunicação não são gestos apartados da experiência e da vida social; 3. A comunicação estratégica não necessariamente irá repercutir em todas as esferas da sociedade que atua, pois, outros dispositivos interacionais existentes na comunidade também afetam os sujeitos, assim, os resultados também diferem conforme o contexto e sujeitos envolvidos e se estão sensíveis, alertas e atentos, dispostos a completar e a participar da construção do sentido projetado; 4. Não existe uma correspondência exata entre o discurso das estratégias de comunicação e o discurso que os sujeitos trocam livremente na vida social; 5 . Os processos estratégicos de comunicação são importantes, mas não são capazes por si só de controlar a dengue, por isso, além da comunicação, outras ações públicas também contribuem para esse sucesso, tais como pesquisas e valorização dos agentes qualificados para esse fim.

Neste contexto, Assis et al. (2013a) argumentam que o padrão de valorização da abordagem do processo saúdedoença em uma perspectiva biomédica e higienista presentes em livros didáticos precisam ser superado a fim de que a saúde seja considerada de maneira mais integrada, daí a importância de se aperfeiçoar os critérios de análise das coleções didáticas de ciências e biologia. Essa análise mais criteriosa pode permitir que esses materiais didáticos sejam eficazes para proporcionar, aos indivíduos, uma perspectiva de ciência direcionada à promoção da saúde e ao exercício consciente da prática social, associada à apropriação cientificamente correta do saber relacionado aos processos de saúde/doença, segundo os autores. Ainda, Assis et al. (2013b) pontuam que o desenvolvimento e disseminação de materiais informativos/educativos de qualidade voltados para o espaço escolar dialoguem com uma perspectiva integrada de educação em saúde. Esses autores ainda acrescentam que a avaliação dos livros didáticos, por meio do PNLD e PNLEM, deve envolver especialistas de diversas áreas, vinculados às universidades e centros de pesquisas, e ainda professores do ensino básico.

Vale destacar que a educação ambiental, já realizada no ambiente escolar, deve ocorrer também nos espaços de atuação do setor saúde, para que nos momentos em que se está instruindo à respeito da promoção ao autocuidado, a população compreenda e valorize a inter-relação entre ambiente, saúde e bem-estar (Busato et al. 2015). Por outro lado, a formação dos professores de ciências também precisa de cuidados, como por exemplo, a reformulação no currículo dos cursos de ciências biológicas para que a educação popular seja discutida também numa perspectiva transversal, entendendo a educação em saúde de forma mais ampla, inclusive com ações de extensão (Pimentel et al., 2020). Entretanto, mesmo com a implementação de todas estas ações, ainda é preciso lembrar da dificuldade que as pessoas têm em assumir novos hábitos de vida saudável, assim é recomendável que além de avaliar o nível de conhecimento de participantes de ações de educação em saúde, sejam utilizados parâmetros avaliativos que permitam medir os hábitos do público alvo para se certificar de que as ações estão sendo efetivas (Paula et al., 2020).

\subsection{Colaboração das instituições de ensino na formação de jovens com vistas à promoção da saúde}

Como evidenciado por vários autores, a participação e colaboração das instituições de ensino na formação e capacitação de crianças, adolescentes e jovens para o combate a dengue e promoção de saúde é crucial para obtenção de medidas efetivas de controle a longo prazo (Assis et al. 2013a; Assis et al. 2013b; Gonçalves et al. 2015; Mafra \& Antunes 2015; Pimentel et al. 2020; Paula et al. 2020)

Para este objetivo, Oliveira (2011), cita alguns pontos relevantes na criação e elaboração de materiais educativos impressos (MEI) sobre dengue, sendo os principais pontos: os discursos e as mensagens sobre a dengue precisam refletir sobre a educação em saúde baseada na liberdade, na autonomia e no diálogo promovendo assim a aproximação do conhecimento 
científico e do senso comum; as etapas de elaboração, circulação, utilização e a avaliação de MEI devem pautar-se no processo de negociação de sentido e significados, portanto, a investigação e valorização das experiências, conhecimentos, atitudes, comportamentos e crenças da população e também de profissionais de saúde e educação, sendo o ideal a reunião de população e profissionais para produzirem e avaliarem os MEI sobre a dengue; as mensagens devem ser claras, em português padrão, mas sem conter termos técnicos ou complexos, dando preferência aos recursos de comunicação que promovam uma interação com o leitor, como perguntas, jogos, diálogos, histórias em quadrinhos (para crianças), onde o leitor se veja também como um interlocutor da mensagem; e finalmente, os MEI não devem conter imagens deturpadas ou monstruosas do mosquito Aedes aegypti ou de pessoas doentes, sendo as figuras apresentadas em escala e autoria, e que retratam situações reais e compatíveis com a realidade da população a que se destina o material.

Outro ponto importante, destacado por Assis et al., (2013b) e Lefevre et al., (2003) é a valorização da compreensão, das percepções e conhecimentos de profissionais de saúde e de professores, pois a estruturação das ações nos setores da educação e da saúde, passa obrigatoriamente por esses sujeitos. Assim, Silva et al. (2013) destaca a importância dos agentes como colaboradores dos pesquisadores na investigação dos quintais, revelando serem grandes parceiros em atividades intersetoriais implantadas no âmbito da Atenção Básica em Saúde.

Ao analisar estes pontos, vemos que a educação em saúde é muito relevante para o controle dos mosquitos vetores, porém é necessário tratar a educação dentro de uma visão mais ampla, chamada de abordagem eco-bio-social, que é uma estratégia compatível com outros métodos de controle e que envolve vários segmentos da sociedade, e, principalmente, tem a educação como uma das áreas estratégicas, sendo um processo educativo de médio e longo prazo, com ações contínuas para garantir a sustentabilidade (Zara et al., 2016, Souza et al., 2019; Macedo et al., 2021). Essa visão holística do problema não é novidade nos textos científicos e, recentemente, tem aumentado o número de publicações com essa visão (Arunachalam et al., 2012; García-Betancourt et al., 2014; Sommerfeld \& Kroeger, 2015; Quintero et al., 2017; Buhler et al., 2019; Quintero et al., 2020; Macêdo et al., 2021). Observa-se nessa metodologia, que as intervenções com engajamento da população requer mais tempo e recursos do que as intervenções tradicionais devido ao tempo investido no processo de socialização e negociação na área alvo para se alcançar a participação das pessoas, além de ter como um elemento importante a educação em saúde, porém, esse investimento resulta em fortes laços com os atores locais que é um fator crítico para a sustentabilidade do controle desse vetor (García-Betancourt et al. 2014, Macêdo et al., 2021).

Finalmente, um estudo feito por Feitosa et al. (2016) levantaram a percepção dos Agentes de Combate às Endemias (ACEs) e gestores acerca do funcionamento do Programa Municipal de Controle da Dengue (PNCD), e identificaram potencialidades e fragilidades das medidas de controle do Aedes aegypti em Aracajú-SE, sendo listadas fragilidades como o reduzido quantitativo e a pouca valorização; a falta de capacitação dos ACEs; a precária intersetorialidade entre os equipamentos e serviços de saúde; as descontínuas estratégias de Educação em Saúde direcionadas à comunidade; as políticas de controle à dengue implantadas são verticalizadas e focadas no controle mecânico e químico, havendo a necessidade de ações participativas e pautadas na Educação Ambiental; focos de pobreza aliados às condições da infraestrutura deficitárias. Além disso, Rangel (2008) acrescenta que as relações trabalhistas dos agentes, a falta de capacitação, a violência urbana/insegurança e outros fatores sociais fragilizam os vínculos de confiança entre agentes públicos e a população. Neste contexto, ambos autores reforçam a necessidade da educação e integração destes agentes e a população, criando na população a consciência de que estes agentes trabalham em colaboração a população e que seu trabalho está diretamente relacionado a busca de qualidade de vida e promoção de saúde.

Para concluir, nós resumimos abaixo todas as alternativas propostas pelos pesquisadores a fim de criar opções e/ou diretrizes que podem ser seguidas em campanhas educativas de controle do mosquito A. aegypti (Tabela 2 e 3). 
Tabela 2. Principais propostas e seus autores para adoção em campanhas educativas para aumento da adesão da população em ações de controle do vetor Aedes aegypti (1998 a 2013).

\begin{tabular}{|c|c|c|c|}
\hline Título do Artigo & Autores & $\begin{array}{l}\text { Periódico (v. n. pp. e } \\
\text { ano) }\end{array}$ & Alternativas para controle dos Aedes aegypti. \\
\hline $\begin{array}{l}\text { Dengue control in Ribeirão } \\
\text { Preto, São Paulo, Brazil. }\end{array}$ & $\begin{array}{l}\text { Passos, AD. et } \\
\text { al. }\end{array}$ & $\begin{array}{l}\text { Cadernos de Saúde } \\
\text { Pública, 14, S123-S128, } \\
1998 .\end{array}$ & $\begin{array}{l}\text { Maior articulação entre políticas públicas (federais, } \\
\text { estaduais e municipais) e população. }\end{array}$ \\
\hline $\begin{array}{l}\text { A survey of knowledge and } \\
\text { attitudes in a population about } \\
\text { dengue transmission - region of } \\
\text { Campinas São Paulo, Brasil - } \\
1998 \text {. }\end{array}$ & $\begin{array}{l}\text { Donalisio, M. et } \\
\text { al. }\end{array}$ & $\begin{array}{l}\text { Rev. Soc. Bras. Med. } \\
\text { Trop. } 34 \text { (2), 197-201, } \\
\text { 2001. }\end{array}$ & $\begin{array}{l}\text { Reorientação das ações educativas. Avaliação constante } \\
\text { (instrumento simplificado) do impacto dos programas } \\
\text { locais de controle. }\end{array}$ \\
\hline $\begin{array}{l}\text { Avaliação sobre a adesão às } \\
\text { práticas preventivas do dengue: } \\
\text { o caso de Catanduva, São } \\
\text { Paulo, Brasil. }\end{array}$ & $\begin{array}{l}\text { Chiaravalloti, } \\
\text { VB. et al. }\end{array}$ & $\begin{array}{l}\text { Cadernos de Saúde } \\
\text { Pública, 18, 1321-1329, } \\
2002 .\end{array}$ & $\begin{array}{l}\text { Valorização do conhecimento populacional. Adaptação da } \\
\text { linguagem teórica para linguagem popular e prática. }\end{array}$ \\
\hline $\begin{array}{l}\text { Dengue prevention: focus on } \\
\text { information. }\end{array}$ & $\begin{array}{l}\text { Lenzi, M \& } \\
\text { Coura, L. }\end{array}$ & $\begin{array}{l}\text { Rev. Soc. Bras. Med. } \\
\text { Trop. 35(1), 221-226, } \\
\text { 2004. }\end{array}$ & $\begin{array}{l}\text { Mudança do caráter campanhista. Divulgação permanente } \\
\text { em multimidias. Esclarecimento de dúvidas da população } \\
\text { em linguagem acessível a todos. Alertar sobre riscos de } \\
\text { doença e automedicação. Colaboração entre instituição de } \\
\text { ensino com vista a promoção da saúde. Papel do setor } \\
\text { público na estrutura do município. }\end{array}$ \\
\hline $\begin{array}{l}\text { Dengue: } \\
\text { comunicação e mobilização na } \\
\text { perspectiva do controle - } \\
\text { propostas inovadoras. }\end{array}$ & Rangel, SML. & $\begin{array}{l}\text { Interface } \\
\text { Comunicação, Saúde e } \\
\text { Educação, 12, 433-441, } \\
2008 \text {. }\end{array}$ & $\begin{array}{l}\text { Campanhas contínuas, não somente em } \\
\text { endemias/epidemias. Promover mudanças culturais na } \\
\text { população, construção de ações democráticas, } \\
\text { descentralizadas e eficientes. Ações de comunicação e } \\
\text { educação devem abarcar: participação democrática. Troca } \\
\text { de conhecimento entre agentes de saúde e população, } \\
\text { promovendo programas de prevenção e promoção da } \\
\text { saúde. Capacitação e condições de exercício aos agentes } \\
\text { de saúde e endemias. Intersetorização das ações: setor } \\
\text { econômico, judicial, saúde e educação. }\end{array}$ \\
\hline $\begin{array}{l}\text { Ações educativas em saúde } \\
\text { para prevenção e controle de } \\
\text { dengue em uma comunidade } \\
\text { periférica da região } \\
\text { metropolitana de Aracaju. }\end{array}$ & $\begin{array}{l}\text { Santos, DM. et } \\
\text { al. }\end{array}$ & $\begin{array}{l}\text { Revista Scientia Plena, } \\
\text { Aracaju, v. } 8(3), 1-8, \\
2012 .\end{array}$ & $\begin{array}{l}\text { Envolvimento das escolas e comunidade em ações } \\
\text { integradas e duradouras. Formação das crianças e } \\
\text { adolescentes (alunos) em agentes de promoção de saúde, } \\
\text { estimulando as ações em seu ambiente domiciliar e } \\
\text { peridomiciliar. }\end{array}$ \\
\hline 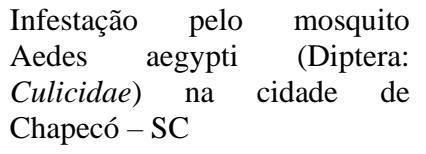 & Lutinski, JA. & $\begin{array}{l}\text { Biotemas 26(2), } 143- \\
151,2013 .\end{array}$ & $\begin{array}{l}\text { Políticas públicas de educação ambiental (resíduos e } \\
\text { água). Campanhas educativas com foco no ambiente } \\
\text { domiciliar. }\end{array}$ \\
\hline $\begin{array}{l}\text { Materiais educativos impressos } \\
\text { sobre dengue: análise quali- } \\
\text { quantitativa e reflexões sobre } \\
\text { comunicação e educação em } \\
\text { saúde. }\end{array}$ & $\begin{array}{l}\text { Oliveira, GLA. } \\
\quad \text { et al. }\end{array}$ & $\begin{array}{l}\text { Encontro Nacional de } \\
\text { Pesquisa em Educação } \\
\text { em Ciências, 7(1), 1-12, } \\
2013 \text {. }\end{array}$ & $\begin{array}{l}\text { Educação formativa e prática; Valorização das } \\
\text { identidades individuais, exercício de comunidade, } \\
\text { dignidade, ética, solidariedade e responsabilidade. } \\
\text { Reforços ao sentimento de pertencer a uma coletividade. } \\
\text { Participação de entidades de cada região (escolas, igrejas, } \\
\text { associação de moradores, etc). Evitar medidas } \\
\text { imediatistas e que somente são realizadas em momentos } \\
\text { de epidemias. }\end{array}$ \\
\hline
\end{tabular}


Tabela 3. Principais propostas e seus autores para adoção em campanhas educativas para aumento da adesão da população em ações de controle do vetor Aedes aegypti (2013 a 2020).

\begin{tabular}{|c|c|c|c|}
\hline Título do Artigo & Autores & $\begin{array}{l}\text { Periódico (v. n. pp. e } \\
\text { ano) }\end{array}$ & Alternativas para controle dos Aedes aegypti. \\
\hline $\begin{array}{l}\text { A dengue nos livros didáticos de } \\
\text { ciências e biologia indicados pelo } \\
\text { Programa Nacional do Livro } \\
\text { Didático. }\end{array}$ & $\begin{array}{l}\text { Assis, SS. et } \\
\quad \text { al. }\end{array}$ & $\begin{array}{l}\text { Ciência \& Educação, } \\
\text { 19(1), 633-656, 2013(a). }\end{array}$ & $\begin{array}{l}\text { Verificar e adequar o conteúdo ministrado sobre a temática } \\
\text { nas escolas. Mudar a perspectiva biomédica e higienista } \\
\text { presente nos livros didáticos, por critérios didáticos numa } \\
\text { perspectiva direcionada a promoção de saúde. }\end{array}$ \\
\hline $\begin{array}{l}\text { Conhecimentos e práticas } \\
\text { educativas sobre dengue: a } \\
\text { perspectiva de professores e } \\
\text { profissionais de saúde. }\end{array}$ & $\begin{array}{l}\text { Assis, SS. et } \\
\quad \text { al. }\end{array}$ & $\begin{array}{l}\text { Ensaio e Pesquisa em } \\
\text { Educação em Ciências, } \\
15,131-153,2013 \text { (b) }\end{array}$ & $\begin{array}{l}\text { Maior diálogo entre cientistas com produção de materiais } \\
\text { educativos modernos e com conceitos corretos e práticos. }\end{array}$ \\
\hline $\begin{array}{l}\text { Contribuições recentes sobre } \\
\text { conhecimentos, atitudes e } \\
\text { práticas da população brasileira } \\
\text { acerca da dengue. }\end{array}$ & $\begin{array}{l}\text { Gonçalves, } \\
\text { RP. et al. }\end{array}$ & $\begin{array}{l}\text { Saúde e Sociedade, } 24, \\
578-593,2015 .\end{array}$ & $\begin{array}{l}\text { Políticas públicas menos verticalizadas. Integração política } \\
\text { de saúde coletiva e população; Educação mais efusiva para } \\
\text { cada contexto socioeconômico e cultural. Empoderar a } \\
\text { população a ocupar posições privilegiadas e efetivas na } \\
\text { construção de políticas de saúde referentes a Dengue. } \\
\text { Desenvolver a responsabilidade individual e coletiva da } \\
\text { população. Corrigir pensamentos e ações errôneas } \\
\text { absorvidas pela população sobre o combate ao mosquito. } \\
\text { Incentivos a educação e promoção em saúde. Promover o } \\
\text { diálogo entre ciência e senso comum. }\end{array}$ \\
\hline $\begin{array}{l}\text { Comunicação, estratégias e } \\
\text { controle da dengue: a } \\
\text { compreensão de um cenário } \\
\text { público de experienciação. }\end{array}$ & $\begin{array}{l}\text { Mafra, } \\
\text { RLM. \& } \\
\text { Antunes, E. }\end{array}$ & $\begin{array}{l}\text { Saúde e Sociedade, } 24 \text {, } \\
977-990,2015 .\end{array}$ & $\begin{array}{l}\text { Interação do poder público e comunidade. Entender que as } \\
\text { ações estratégicas não repercutem em todas as esferas } \\
\text { imediatamente obtendo diferentes resultados. Observar que } \\
\text { as ações estratégicas de comunicação, apesar de } \\
\text { importantes, não controlam a doença sozinhas, sendo } \\
\text { necessário o envolvimento de todos imediatamente. } \\
\text { Importância da participação social e efetiva da sociedade. }\end{array}$ \\
\hline $\begin{array}{l}\text { Reflections on the relationship } \\
\text { health and environment: the } \\
\text { perception of a community. }\end{array}$ & $\begin{array}{l}\text { Busato, M. } \\
\quad \text { et al. }\end{array}$ & Holos, 6,460-471, 2015. & $\begin{array}{l}\text { Educação ambiental não só no ambiente educacional, mas } \\
\text { no ambiente de saúde, promovendo saúde e bem-estar. }\end{array}$ \\
\hline $\begin{array}{l}\text { Estratégias de prevenção e } \\
\text { controle da Dengue em Aracajú } \\
\text { potencialidades e fragilidades. }\end{array}$ & $\begin{array}{l}\text { Feitosa, } \\
\text { FRS. et al. }\end{array}$ & $\begin{array}{l}\text { Caminhos de Geografia, } \\
17,149-168,2016 .\end{array}$ & $\begin{array}{l}\text { Capacitação e valorização dos Agentes de Combate a } \\
\text { Endemias (ACE); Autonomia dos ACEs para resolver } \\
\text { problemáticas relacionadas ao combate e requisições da } \\
\text { população. }\end{array}$ \\
\hline 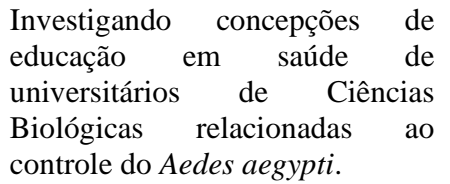 & $\begin{array}{l}\text { Pimentel, } \\
\text { AG. et al. }\end{array}$ & $\begin{array}{l}\text { Revista de Educação } \\
\text { Popular, 13(6), 83-103, } \\
2020 .\end{array}$ & $\begin{array}{l}\text { Educação e saúde em todos os níveis educacionais (ensino } \\
\text { fundamental - superior). }\end{array}$ \\
\hline
\end{tabular}

Fonte: Autores.

\section{Considerações Finais}

A baixa adesão da população às recomendações do poder público tem sido atribuída, principalmente, à condução de programas de controle chamados de campanhistas, devido à centralização de ações e tomadas de decisão pelo poder público. Neste cenário, a educação é apontada como importante elemento para o engajamento das pessoas de forma a diminuir a distância entre o conhecimento e as ações efetivas de controle do mosquito.

A presença do poder público cuidando dos seus espaços, manejando o ambiente para que não favoreça a proliferação do mosquito, além de fornecimento de infraestrutura de fornecimento de água e esgoto e recolhimento de resíduos sólidos e orgânicos também contribuem para o engajamento da população.

A melhoria na formação dos professores de ciências, bem como na melhoria da qualidade dos materiais educativos e o desenvolvimento de metodologias de aprendizagem mais eficientes são itens fundamentais para que a educação em saúde possa contribuir efetivamente para o controle desse vetor. 
Os agentes de endemia precisam ser ouvidos e compreendidos quanto a sua percepção dos programas de controle, pois eles estão mais intimamente ligados ao público alvo. Esses profissionais transmitem à comunidade a sua visão sobre o problema, assim, o seu empoderamento resulta em um maior engajamento desse ator social que irá agir nos lares para estimular a adesão das pessoas às práticas cotidianas de eliminação dos criadouros.

Por fim, a abordagem holística no combate ao mosquito A. aegypti possibilita alocar cada elemento desse processo na sua devida proporção; nem mesmo a educação, com toda a sua influência no ambiente escolar e nos lares, é a solução mágica para esse problema, antes é um elemento importante que se articulado a outros setores da sociedade pode trazer resultados muito mais significativos para o combate à tríplice epidemia.

Dentro deste contexto, nosso grupo de pesquisa objetiva como trabalhos futuros, uma continuidade na avaliação das metodologias de controle de arbovírus através de estudos de parceria entre Universidade e os sistema de vigilância e controle de zoonoses dos municípios, com atividades de colaboração e avaliação mensal das ações realizadas, capacitação técnica de colaboradores, visitas técnicas, produção de material de educação para adultos e crianças sobre a temática, bem como outras atividades pontuais que possam ser demandadas pelas secretarias de saúde dos municípios atendidos/avaliados.

\section{Referências}

Aragão, C. F. et al. (2019). Natural Infection of Aedes aegypti by Chikungunya and Dengue type 2 Virus in a Transition Area of North-Northeast Brazil. Viruses. 11(12), 1126. https://www.mdpi.com/1999-4915/11/12/1126.

Araújo, H. R. C. et al. (2015). Aedes aegypti Control Strategies in Brazil: Incorporation of New Technologies to Overcome the Persistence of Dengue Epidemics. Insects, 6(2), 576-594. https://www.mdpi.com/2075-4450/6/2/576,

Arunachalam, N. el al. (2012). Community- based control of Aedes aegypti by adoption of eco- health methods in Chennai City, India. Pathogens and global health. 106(8), 488-496. https://www.ncbi.nlm.nih.gov/pmc/articles/PMC3541894/.

Assis, S. S.; Pimenta, D. N. \& Schall, V. T. (2013). A dengue nos livros didáticos de ciências e biologia indicados pelo Programa Nacional do Livro Didático. Ciência \& Educação. 19(3), 633-656. https://www.scielo.br/scielo.php?script=sci_arttext\&pid=S1516-73132013000300009.

Assis, S. S.; Pimenta, D. N. \& Schall, V. T. (2013). Conhecimentos e práticas educativas sobre Dengue: A perspectiva de professores e profissionais de saúde. Ensaio Pesquisa em Educação em Ciências. 15(1), 131-153. https://www.scielo.br/pdf/epec/v15n1/1983-2117-epec-15-01-00131.pdf.

Brasil, Ministério da Saúde, Portal da saúde, seção cidadão, Programa Nacional de Controle da Dengue. http://bvsms.saude.gov.br/bvs/publicacoes/pncd_2002.pdf.

Brassolatti, R. C. \& Andrade, C. F. S. (2012). Avaliação de uma intervenção educativa na prevenção da dengue. Ciência \& Saúde Coletiva. 7(2), 243-251. https://www.scielo.br/scielo.php?script=sci_arttext\&pid=S1413-81232002000200005.

Brito, J. et al. (2020). After 10 years the myth of Crotalaria spp. and dragonflies remains alive. Biota Neotropica. 20(2), e20190907. https://www.scielo.br/scielo.php?script=sci_arttext\&pid=S1676-06032020000200401.

Buhler, C. V. et al. (2019). Environmental methods for dengue vector control - A systematic review and meta-analysis. PLoS Neglected Tropical Diseases. 13(7), e0007420, https://www.ncbi.nlm.nih.gov/pmc/articles/PMC6650086/.

Busaro, M. A.; Ferraz, L \& Frank, N. L. P. (2015). Reflexões sobre a relação saúde e ambiente: A percepção de uma comunidade - Reflections on the relationship health and environment: the perception of a community. HOLOS. 6, 460-471. http://www2.ifrn.edu.br/ojs/index.php/HOLOS/article/view/2145.

Caprara, A. et al. (2015). Entomological impact and social participation in dengue control: a cluster randomized trial in Fortaleza, Brazil. Transactions of The Royal Society of Tropical Medicine and Hygiene. 109(2), 99-105. https://www.ncbi.nlm.nih.gov/pmc/articles/PMC4299523/.

Carneiro, F. F. et al. (2016). Successful experience in the control of Aedes aegypti without the use of poisons in Ceara backcountry. Vigilância Sanitária em Debate-Sociedade Ciência \& Tecnologia. 4(2), 126-131. https://cevs.rs.gov.br/upload/arquivos/201808/27130322-carneiro-et-al-2016-experiencia-bemsucedida-no-controle-do-aedes-aegypti-sem-uso-de-venenos.pdf.

Chaves, M. O.; Evangelista, M. S. N. \& Fernandes, F. M. C. (2020). Educação em saúde sobre o Aedes aegypti: relato de experiência. Revista Brasileira de Enfermagem. 73(3), e20180487. https://www.scielo.br/scielo.php?script=sci_arttext\&pid=S0034-71672020000300501\&lng=en\&nrm=iso\&tlng=pt

Chiaravalloti, V. B. et al.(2002). Avaliação sobre a adesão às práticas preventivas do dengue: o caso de Catanduva, São Paulo, Brasil. Cadernos de Saúde Pública. 18(5), 1321-1329. https://www.scielo.br/scielo.php?script=sci_arttext\&pid=S0102-311X2002000500025\&lng=en\&nrm=iso\&tlng=pt

Donalisio, M. R. \& Visockas, M. J. A. (2001). A survey of knowledge and attitudes in a population about dengue transmission - region of Campinas São Paulo, Brasil - 1998. Revista da Sociedade Brasileira de Medicina Tropical. 34(2), 197-201. https://www.scielo.br/scielo.php?script=sci_arttext\&pid=S003786822001000200008 . 
Feitosa, F. R. S. et al. (2016) Estratégias de prevenção e controle da dengue em Aracajú: Potencialidades e fragilidades. Caminhos de Geografia. 17(60), 149168. http://www.seer.ufu.br/index.php/caminhosdegeografia/article/view/34690.

Fernandes, V. R. et al. (2017). The 'locus' of health oversight in Brazil's Unified Health System a place between the knowledge and the practices of social mobilization.(Ensayo). Ciência \& Saúde Coletiva. 22(10), 3173-3181. https://www.scielo.br/scielo.php?pid=S1413$81232017021003173 \&$ script=sci_arttext\&tlng=en

Ferreira, B. J. et al. (2009). Evolução histórica dos programas de prevenção e controle da dengue no Brasil. Ciência \& Saúde Coletiva. 14(3), 961-972. https://www.scielo.br/scielo.php?pid=S1413-81232009000300032\&script=sci_abstract\&tlng=pt.

García-Betancourt, T. C. et al. (2014). Ecobiosocial Community Intervention for Improved Aedes aegypti Control Using Water Container Covers to Prevent Dengue: Lessons Learned from Girardot Colombia. EcoHealth. 11(3), 434-438. https://link.springer.com/article/10.1007/s10393-014-0953-8.

Gonçalves, R. P. et al. (2015). Contribuições recentes sobre conhecimentos, atitudes e práticas da população brasileira acerca da dengue. Saúde e Sociedade. 24(2), 578-593. https://www.scielo.br/scielo.php?script=sci_arttext\&pid=S0104-12902015000200578\&lng=en\&nrm=iso\&tlng=pt.

Heydari, N. et al. (2017). Household Dengue Prevention Interventions, Expenditures, and Barriers to Aedes aegypti Control in Machala, Ecuador. International Journal of Environmental Research and Public Health. 14(2), 196. https://www.ncbi.nlm.nih.gov/pmc/articles/PMC5334750/.

Heymann, D. L.\& Dar, O. A. (2014). Prevention is better than cure for emerging infectious diseases. BMJ. 349 https://www.bmj.com/content/348/bmj.g1499.long.

Honório, N. A. et al. (2020). High-Throughput Method for Detection of Arbovirus Infection of Saliva in Mosquitoes Aedes aegypti and Ae. albopictus. Viruses. 12(11), 1343. https://www.ncbi.nlm.nih.gov/pmc/articles/PMC7700541/.

Oliveira, J. C. \& Lima, S. C. (2013) Mobilização comunitária e vigilância em saúde no controle de vetores, estratégias da promoção da saúde: conquistas e desafios. Revista de educação popular. 12(1). http://www.seer.ufu.br/index.php/reveducpop/article/view/23029.

Lefevre, A. M. C. et al. (2003) Representações dos agentes de combate ao Aedes aegypti sobre a estratégia de retirada do inseticida nas ações de controle do vetor. Revista Brasileira de Epidemiologia. 6(4), 359-372. https://www.scielo.br/scielo.php?script=sci_arttext\&pid=S1415790X2003000400010\&lng=en\&nrm=iso\&tlng=pt.

Lenzi, M. F. \& Coura, L. C. (2004) Dengue prevention: focus on information. Revista da Sociedade Brasileira de Medicina Tropical. 37(4), 343-350. https://www.scielo.br/scielo.php?script=sci_arttext\&pid=S0037-86822004000400011\&lng=pt\&tlng=pt.

Lutinski, J. A. et al (2013). Infestação pelo mosquito Aedes aegypti (Diptera: Culicidae) na cidade de Chapecó - SC. Biotemas. 26(2), 143-151. https://periodicos.ufsc.br/index.php/biotemas/article/view/21757925.2013v26n2p143\#: :text=Este\%20estudo\%20visou\%20a\%20avaliar,na\%20cidade\%20de \%20Chapec\%C3\%B3\%20\%E2\%80\%93\%20SC.\&text=As\%20an\%C3\%A1lises\%20indicam\%20a\%20associa\%C3\%A7\%C3\%A3o,como\%20com\%20o\%20a mbiente\%20residencial.

Ludke, M. \& Andre, M. E. D. A. (2013). Pesquisas em educação: uma abordagem qualitativa. E.P.U.

Macêdo, S. F. et al. (2021). Scaling up of Eco-Bio-Social Strategy to Control Aedes aegypti in Highly Vulnerable Areas in Fortaleza, Brazil: A Cluster, NonRandomized Controlled Trial Protocol. International Journal of Environmental Research and Public Health. 18(3), 1278. https://www.ncbi.nlm.nih.gov/pmc/articles/PMC7908398/.

Madeira, N. G. et al. (2002). Education in primary school as a strategy to control dengue. Revista da Sociedade Brasileira de Medicina Tropical, 35(3), 221226. https://www.scielo.br/scielo.php?script=sci_arttext\&pid=S0037-86822002000300004

Mafra, R. L. M. \& Antunes, E. (2015). Comunicação, estratégias e controle da dengue: a compreensão de um cenário público de experienciação. Saúde e Sociedade. 24(3), 977-990. https://www.scielo.br/scielo.php?script=sci_arttext\&pid=S0104-12902015000300977\&lng=en\&nrm=iso\&tlng=pt.

Mazzoti - Alves, A. J. \& Giewndsznayder, F. (2002). O método das ciências sociais: Pesquisa quantitativa e qualitativa, Editora Pioneira.

Mukherjee, D. et al. (2019). The Mosquito Immune System and the Life of Dengue Virus: What We Know and Do Not Know. Pathogens. 8(2), 77. https://www.ncbi.nlm.nih.gov/pmc/articles/PMC6631187/.

Armindo, G. L.; Diniz, M. C. P. \& Schall, V. T. (2011). Materiais educativos impressos sobre dengue: análise quali-quantitativa e reflexões sobre comunicação e educação em saúde. Encontro Nacional de Pesquisa em Educação em Ciências (Florianópolis). 7(1), 1-12. https://www.arca.fiocruz.br/handle/icict/16306.

Paula, C. R. et al. (2020). Arte em defesa da vida. Revista Em Extensão. 19(1), 172-183. http://www.seer.ufu.br/index.php/revextensao/article/view/51266>. Pereira A. S. et al. (2018). Metodologia da pesquisa científica. UFSM.

Pimente, A. G. et al. (2020), Investigando concepções de educação em saúde de estudantes universitários de Ciências Biológicas relacionadas ao controle do Aedes aegypti. Revista de Educação Popular. Uberlândia, p. 83-103. http://seer.ufu.br/index.php/reveducpop/article/view/53289/29423. 2021.

Purnama, S. G. et al. (2020). Knowledge, Attitudes and Practices towards the Density of Aedes Larvae in a Tourist Destination in Bali. Asian Journal of Education and Social Studies. 13(4), 22-32. https://www.journalajess.com/index.php/AJESS/article/view/30338.

Quintero, J. et al. (2020). Effectiveness of an intervention for Aedes aegypti control scaled- up under an inter- sectoral approach in a Colombian city hyperendemic for dengue virus. PLOS ONE. 15(4), e0230486. https://www.ncbi.nlm.nih.gov/pmc/articles/PMC7112230/.

Quintero, J. et al. (2017). Taking innovative vector control interventions in urban Latin America to scale: lessons learnt from multi- country implementation research. Pathogens and global health. 111(6), 306-316. https://www.ncbi.nlm.nih.gov/pmc/articles/PMC5694858/. 
Research, Society and Development, v. 10, n. 9, e10810917912, 2021

(CC BY 4.0) | ISSN 2525-3409 | DOI: http://dx.doi.org/10.33448/rsd-v10i9.17912

Rangel, S. M. L. (2008). Dengue: educação, comunicação e mobilização na perspectiva do controle - propostas inovadoras. Interface - Comunicação, Saúde, Educação. 12(25), 433-441. https://www.scielo.br/scielo.php?pid=S1414-32832008000200018\&script=sci_abstract\&tlng=pt.

Reis, C. B.; Andrade, S. M. O. \& Cunha, R. V. (2013). Aliados do A. Aegypti: fatores contribuintes para a ocorrência da dengue segundo as representações sociais dos profissionais das equipes de saúde da família. (TEMAS LIVRES). Ciência \& Saúde Coletiva. 18(2), 517-526. https://www.scielo.br/scielo.php?script=sci_arttext\&pid=S1413-81232013000200023.

Sales, F. M. S. (2008) Ações de educação em saúde para prevenção e controle da dengue: um estudo em Icaraí, Caucaia, Ceará. Ciência \& Saúde Coletiva. 13(1), 175-184. https://www.scielo.br/scielo.php?script=sci_arttext\&pid=S1413-81232008000100022\&lng=en\&nrm=iso\&tlng=pt.

Santos, D. M. et al. (2012). Ações educativas em saúde para prevenção e controle de dengue em uma comunidade periférica da região metropolitana de Aracaju. Revista Scientia Plena, 8(3), 1-8. https://www.scientiaplena.org.br/sp/article/view/890.

Silva, P. C.; Martins, A. M. \& Schall, V. T. (2013). Cooperação entre agentes de endemias e escolas na identificação e controle da dengue. Revista Brasileira em Promoção da Saúde, 26(3), 404-41. 2013. https://periodicos.unifor.br/RBPS/article/view/2948\#: :text=Conclus\%C3\%A30\%3A\%20O\%20estudo\%20dem onstra\%20o,intersetorialidade\%20na\%20preven\%C3\%A7\%C3\%A3o\%20da\%20dengue.

Sommerfeld, J. \& Kroeger, A. (2015). Innovative community-based vector control interventions for improved dengue and Chagas disease prevention in Latin America: introduction to the special issue. Transactions of The Royal Society of Tropical Medicine and Hygiene, 109(2), 85-88. , 2015. https://www.ncbi.nlm.nih.gov/pmc/articles/PMC4299521/.

Souza, R. Mosquito volta à Pedra Branca. Diário do Nordeste, Fortaleza 24 de Julho 2017. https://diariodonordeste.verdesmares.com.br/regiao/mosquitovolta-a-pedra-branca-1.1793302

Souza, T, G. B. et al., (2019). Programa saúde na escola - ações de combate ao mosquito Aedes aegypti. Brazilian Journal of Development 5(1), $20189-20198$.

Sulisityawati, S. et al. (2019). Dengue Vector Control through Community Empowerment: Lessons Learned from a Community-Based Study in Yogyakarta, Indonesia. International Journal of Environmental Research and Public Health. 16(6), 1013. https://www.ncbi.nlm.nih.gov/pmc/articles/PMC6466136/.

Zara, A. L. S. A et al.(2016). Aedes aegypti control strategies: a review. Epidemiologia e Servicos de Saúde. 25(2), 391-404. https://www.scielo.br/scielo.php?script=sci_arttext\&pid=S2237-96222016000200391. 